\title{
Expert Review of Proteomics
}

\section{Advances in mass spectrometry-based cancer research and analysis: from cancer proteomics to clinical diagnostics}

\author{
John F. Timms, Oliver J. Hale \& Rainer Cramer
}

To cite this article: John F. Timms, Oliver J. Hale \& Rainer Cramer (2016): Advances in mass spectrometry-based cancer research and analysis: from cancer proteomics to clinical diagnostics, Expert Review of Proteomics, DOI: 10.1080/14789450.2016.1182431

To link to this article: http://dx.doi.org/10.1080/14789450.2016.1182431

Accepted author version posted online: 24 Apr 2016.

Submit your article to this journal $₫$

Џ Article views: 2

Q View related articles $₫$

View Crossmark data $\nearrow$ 


\title{
Publisher: Taylor \& Francis
}

Journal: Expert Review of Proteomics

DOI: $10.1080 / 14789450.2016 .1182431$

Title: Advances in mass spectrometry-based cancer research and analysis: from cancer proteomics to clinical diagnostics

Authors: John F. Timms ${ }^{1}$, Oliver J. Hale ${ }^{2}$ and Rainer $\mathrm{Cramer}^{2} *$

${ }^{1}$ Department of Women's Cancer, Institute for Women's Health, University College London, UK

${ }^{2}$ Department of Chemistry, University of Reading, UK

* Corresponding author:

Email: r.k.cramer@reading.ac.uk phone: +44 1183784550

fax: +44 1183786331

\begin{abstract}
Introduction: The last 20 years have seen significant improvements in the analytical capabilities of biological mass spectrometry (MS). Studies using advanced MS have resulted in new insights into cell biology and the etiology of diseases as well as its use in clinical applications.
\end{abstract}

Areas covered: This review discusses recent developments in MS-based technologies and their cancerrelated applications with a focus on proteomics. It also discusses the issues around translating the research findings to the clinic and provides an outline of where the field is moving.

Expert commentary: Proteomics has been problematic to adapt for the clinical setting. However, MS-based techniques continue to demonstrate potential in novel clinical uses beyond classical cancer proteomics.

\section{Keywords}

Mass spectrometry, cancer research, cancer proteomics, clinical diagnostics, clinical mass spectrometry, mass spectrometry imaging, REIMS, MALDI, biotyping, pharmacokinetics 


\section{MS-Based Cancer Proteomics - An Overview}

The field of mass spectrometry (MS)-based proteomics has undeniably contributed to our knowledge of biological systems and has allowed us to characterise them in far greater detail than would have been possible using conventional analytical strategies. In the field of cancer research alone, there have been over 12,000 research and review articles published in the last 20 years where the term proteomics is cited, with the vast majority reporting data obtained by MS analysis. MS-based technologies have been used to study the molecular mechanisms of cancer through examination of specific gene function and regulation, to interrogate deregulated signalling pathways in cancer, to define molecular sub-types of tumours, to map cancer-associated protein interaction networks and post-translational modifications, to aid in the development of new therapeutics or imaging tools and particularly of new diagnostic and prognostic tests through the identification of cancer biomarkers.

In the study of the molecular mechanisms of cancer, proteomic profiling is frequently employed to compare the relative abundances of proteins between two or more relevant biological or clinical samples and thereby to infer the involvement of particular proteins in specific biological processes that contribute to cellular transformation or cancer progression. Samples from a variety of sources have been used including cultured cell models, mouse models, primary cells, tumour tissues and body fluids such as serum, plasma, urine and bile. Profiling of biospecimens has to date largely employed 'bottom-up' MS approaches, where at some point in the workflow the protein sample is proteolytically digested into its constituent peptides prior to MS analysis: peptides are more amenable to identification and chemical characterisation using MS (Figure 1). Liquid chromatography (LC) electrospray ionisation (ESI) tandem mass spectrometry (MS/MS) is the method of choice for bottom-up proteomics, with improvements in MS instrument speed, sensitivity, mass accuracy and resolution now providing an unparalleled depth of coverage of the proteome and allowing detailed chemical characterisation of multiple proteoforms [1-3].

Extensive fractionation and/or enrichment are usually required to achieve high-depth coverage of complex biological specimens. Bottom-up proteomics has been largely driven by data-dependent acquisition (DDA), where the most abundant peptide precursor ions entering the mass spectrometer are selected for fragmentation and identification. Since tandem instruments have a finite cycle time, not all peptide ions can be selected, resulting in considerable under-sampling. Increasing resolving power through orthogonal multidimensional LC separation is thus required to simplify the mixture of peptide ions entering the analyser at a given time during the chromatography such that under-sampling and ion suppression are minimised and dynamic range can be improved [4] (Figure 1). Whilst the analysis of multiple fractions is a necessity for improving coverage, it comes at the cost of longer analysis times. However, continued improvements in instrument sensitivity, selectivity and speed are now making high-coverage analysis of low amounts of complex samples possible without the need for extensive fractionation and/or analysis time. 
In 'top-down' proteomics, protein identification is obtained directly from fragmentation (and possibly other information) of the intact proteins. Theoretically, this provides the richest data for both identification and full characterization of molecular composition and is a useful targeted approach for the study of cancer-associated proteins. However, it is considerably more challenging to execute than bottom-up approaches because of the complexity of the data generated and is generally restricted to proteins $<30 \mathrm{kDa}$ due to MS resolution limitations and offers lower proteome coverage of complex samples. Despite this, a top-down approach was shown to provide additional molecular information when combined with a bottom-up approach in the characterisation of patient-derived xenograft models of different breast tumour sub-types [5].

Proteomic profiling by LC-MS/MS must incorporate a means of quantification and numerous methods have been reported [6]. Briefly, they fall into two categories: label-free and those using protein or peptide labelling, known as differential mass tagging or isotopic labelling (Figure 1). Most strategies employ relative quantification, although methods for absolute quantification are possible through the introduction of known amounts of internal standards, as used in methods such as selected and multiple reaction monitoring (S/MRM), which are discussed later. Label-free approaches involve comparison of peptide ion signal intensities between samples or comparison of spectral counts for peptide ions matching a particular protein. In terms of quantitative accuracy, label-free approaches are more dependent on chromatographic reproducibility requiring detection and matching of the same ions across runs [7]. In contrast, chemical labelling strategies such as TMT [8], iTRAQ [9] or dimethyl labelling [10], and in vivo labelling strategies such as SILAC [11], rely on the use of stable isotope-labelled reagents that allow mixing of two or more differentially labelled samples prior to LC-MS, with ion signal intensities directly comparable in the same MS or MS/MS scans. Use of labelling strategies thus improves throughput and potentially quantitation accuracy. Whilst clinical specimens such as tumour tissues and body fluids are generally not amenable to in vivo labelling, in vivo-labelled reference material (from relevant cell lines for example) has been used for comparative studies, as exemplified by the super SILAC method [12]. Example workflows for LC-MS-based profiling in cancer research are presented in Figure 1.

LC-MS/MS-based protein expression profiling has been recently used to compare the proteomes of normal, benign and malignant tissue specimens to a depth of coverage of $>9,000$ gene products $[13,14]$. Such large-scale studies are implicating the cellular processes and metabolic pathways involved in tumour development and progression on a near genome-wide scale. Proteomics has also been integrated with genomics, transcriptomics and bioinformatics in so called proteogenomics, providing complementary and detailed molecular information linking cancer genotype and phenotype on an individualised level $[15,16]$. A commendable example of this was the profiling of 95 colorectal tumours previously characterised by The Cancer Genome Atlas [17]. Somatic variants displayed reduced protein abundance compared to germline 
variants, whilst copy number alterations or mRNA transcript levels did not reliably predict protein abundance across the tumour set. Five proteome subtypes were identified, two of which overlapped with previously defined transcriptomic subtypes, but had distinct mutation, methylation and protein expression patterns associated with clinical outcome. Several potential driver genes were also identified. By overcoming disparities between mRNA and protein abundances and by allowing the identification of tumour-associated post-translational modifications, proteomics has the potential to identify novel gene products involved in malignancy, to determine therapeutic targets and to facilitate the discovery of novel diagnostic and prognostic markers. It is important to note here that bioinformatics analysis of these large datasets can only infer the functional involvement of differentially expressed proteins in cancer-specific processes and the onus is now on researchers to functionally validate the findings of these studies.

The analysis of biofluids by MS-based proteomics is particularly challenging owing to their very broad dynamic range of protein abundance. A way to improve coverage in DDA has been to immunodeplete the most abundant proteins using immobilised antibodies [18]. Whilst concerns have been raised about the loss of protein species bound to proteins targeted for depletion and the reproducibility of parallel depletions, it is generally accepted that the increased coverage afforded by immunodepletion outweighs these shortcomings. Immobilised combinatorial peptide libraries have also been used to 'equalise' protein abundances in biofluid specimens and work by presenting a limited number of binding sites for theoretically all proteins in the sample [19]. Binding sites for abundant proteins become saturated and excess of these proteins are removed, whilst lower abundance species are enriched. However, by its concept this approach is inherently limited for quantitative analyses.

The enrichment of specific sub-proteomes such as phosphoproteins and glycoproteins has also been used to improve the depth of coverage and identify expression changes and alterations in post-translational modifications relevant to cancer. Various methods for sub-proteome enrichment have been reviewed in more detail elsewhere [20-23]. In one example, phosphopeptide enrichment and TMT-labelling were used with LC-MS/MS to profile pancreatic tumour and adjacent normal tissue specimens [24]. Tumour-specific changes in protein expression and phosphorylation were revealed. Activator phosphorylation sites on several known drug targets implicated them as targets for individualised therapy. In another impressive example, the response of 13,405 phosphopeptides to a panel of small-molecule kinase inhibitors was assessed using a label-free approach [25]. The study revealed the topology and activity of different signalling networks and showed how kinase networks were remodelled in inhibitor-resistant cells reflecting their evolved phenotypes. Lectin affinity enrichment or hydrazide chemistry capture combined with enzymatic release of glycopeptides coupled with quantitative LC-MS/MS has been used for the identification of altered $\mathrm{N}$-glycosylation and glycoprotein expression in a variety of cancer types [26-29], whilst identification of substrates and altered activities of tumour-specific proteases has been achieved 
using peptide library screening, exogenous reporter substrates or labelling and enrichment of proteasegenerated $\mathrm{N}$-termini [30].

MS has also become an indispensable tool for characterising immunopeptidomes, i.e. the collection of peptides associated with and presented by human leukocyte antigen (HLA) molecules [31,32]. Using cancer cell models or clinical specimens combined with various enrichment methods, it is now possible to rapidly and comprehensively define the repertoires of cancer-associated peptides presented by HLA molecules. In a recent example, immunoprecipitation and LC-MS/MS in DDA mode was used to define acute myeloid leukaemia (AML)-associated peptide vaccine targets by comparing eluted peptides from AML patient and healthy donor mononuclear cells [33]. Over 25,000 different presented ligands were identified and prioritised based on AML exclusivity and presentation frequency. Functional characterisation of tumourassociated peptides confirmed AML-specific T-cell recognition. These types of study are providing the knowledge to guide the development of novel anti-cancer immunotherapies [34].

MS-based metabolic profiling is worth mentioning here in the context of exploring the mechanisms of cancer and for cancer biomarker discovery. Solvent extraction, protein removal and chemical derivatisation are coupled with LC-MS/MS and/or GC-MS to acquire metabolite profiles from any sample type, with molecular identification and quantification achieved using spectral Vibraries and labelled standards [35]. As examples in the cancer field, metabolomic profiling was used to identify sarcosine as a driver of prostate cancer aggressiveness [36], an ultra-long-chain fatty acid as a potential serum marker of pancreatic cancer [37] and (R)-2-hydroxyglutarate as an 'oncometabolite' generated by mutant forms of IDH1 and 2 found in cancer [38]. In the near future, the integration of metabolomic and proteogenomic information will provide a truly holistic view of biological systems, allowing the linkage of genotype with phenotype on an individual level that will drive personalised medicine.

\section{Proteomic Cancer Biomarker Discovery - The Failure of Proteomics and Solutions}

Cancer biomarkers are categorised by their ability to discriminate malignancy from the healthy or benign state, and thereby can be used for diagnosis, early detection and monitoring disease recurrence. Biomarkers can also be used for prognosis or to predict response to therapy, and may also aid in understanding the biological mechanisms underlying tumour development and progression. One research area where MS-based proteomics is used intensively is in cancer biomarker discovery (e.g. [39-43]), yet the field of MS-based proteomics has delivered few cancer biomarkers that have been translated to clinical use [44]. It may be the case that the 'best' tumour markers have already been found and further discovery, even at a level covering the whole proteome with detailed characterisation of all proteoforms, will be fruitless. However, there is still hope since it is likely that the performance of existing biomarkers (e.g. PSA, 
CA125, CEA and CA19-9) could be improved by combining them with additional markers and using novel biomarker modelling methods.

Cancer is a complex and heterogeneous disease and this certainly contributes to the failure of proteomics in delivering useful biomarkers. Related to this, any specific tumour type is likely to display different molecular characteristics from one patient to another patient with individuals responding differently to the presence of the tumour. Such differences are largely driven by genetic and epigenetic variation, so the emerging technologies and approaches that combine proteomics, genomics, epigenomics and metabolomics are likely to benefit biomarker discovery enormously through the investigation of molecular changes at an individualised level. In turn, personalised medicine will benefit from an individualised biomarker-based approach.

In addition to the inherent molecular heterogeneity of cancer, the reasons for the failure of MS-based and indeed targeted proteomic approaches to deliver biomarkers are centred on the limitations of current proteomic strategies and compromises in study design. Below, we discuss these limitations and offer suggestions on how to improve the chances of successful cancer biomarker discovery. We also provide the few examples of successes in proteomic cancer biomarker discovery and discuss emerging technologies that may improve the success rate.

Firstly, it is recognised that existing proteomic technologies do not adequately deal with the complexity and extremely wide dynamic range of expression of the human proteome. This is a particular issue with biofluid specimens such as serum, where the dynamic range of protein abundance may be 10 orders of magnitude with relatively few abundant proteins contributing the majority of total protein. Additionally, potential tumour-specific proteins secreted or released from a tumour are massively diluted in the circulation. In essence, we may be failing to cover the proteome to a sufficient depth of sensitivity and are thus missing proteoforms with biomarker potential. Secondly, many published discovery studies have failed to employ well-characterised, sufficiently numerous, high-quality or even relevant clinical samples. Case control samples should be carefully matched by collection protocol, age, gender, drug use and other potential confounding factors. Sufficient numbers of samples should be used to adequately power a study. False discovery rates should be reported and corrections made for multiple testing when candidate selection is undertaken. Variability introduced by sample handling is of particular concern. For serum especially, the low-molecular weight proteome has been shown to be highly sensitive to handling conditions [45-48], where differential proteolysis is the main driver of this pre-analytical variability. Thus, standardised protocols must be employed to ensure that collection, handling and storage of all samples is carried out identically (e.g. see $[43,49,50])$. This may be difficult to achieve in practice and requires the coordinated support of clinicians and research nurses. Tissue heterogeneity also limits the value of information available from the proteomic analysis of tumour specimens. Unprocessed tumour tissue 
specimens are often heterogeneous at the cellular level and are often 'contaminated' with blood. Microdissection and histopathological examination to confirm cellular purity is thus essential to any proteomic discovery effort and methods such as laser-capture microdissection, whilst laborious, can be used to procure more homogeneous, high-quality specimens [51]. Proteomic analysis of archived formalinfixed, paraffin-embedded (FFPE) specimens has also proved to be a feasible approach for biomarker discovery despite concerns about variability in fixation, fixation-induced protein modification and protein extraction [52]. The longevity and morphological stability of FFPE tissues, the accumulation of archives linked to clinical patient data and pathologist-directed microdissection provides an invaluable resource for retrospective biomarker studies employing proteomic technologies.

Lack of use of appropriate controls is a particular problem in discovery studies and it is essential that specimens are selected based on the intended use of the biomarker. For cancer diagnosis in the clinical setting, biomarkers must differentiate between cases of malignant and benign disease presenting with similar symptoms or that show similar findings upon imaging. Many discovery studies have used only healthy control specimens, and since candidate markers may be similarly altered in benign conditions with shared indications, potential candidates are likely to lack diagnostic specificity. As an example, an appropriately controlled proteomic study showed the influence of obstructive jaundice on the performance of diagnostic biomarkers for pancreatic cancer [53]. Similarly, inflammatory response markers are repeatedly found in proteomic cancer biomarker studies. Whilst this is undoubtedly due to an inflammatory response to the tumour, such markers may lack specificity and should be validated against controls from inflammatory conditions. For prognostic biomarker discovery, only specimens from patients with clearly defined endpoints should be used, whilst biomarker studies looking at treatment response or recurrence benefit greatly from the use of Yongitudinal samples [54]. In the search for early detection/screening markers, samples pre-dating diagnosis should ideally be used. This has been achieved using samples from on-going screening programs or trials $[42,55]$ and is a means of reducing the false discovery of late stage, non-specific markers.

Thirdly, and perhaps most importantly, many biomarkers or multi-marker classifiers arising from proteomic discovery are not properly validated using independent samples or are not compared with the gold standard biomarker test. Furthermore, biomarker panels may have failed validation, but are not reported. Independent researchers may be wasting effort in reassessing the same potential biomarkers. A paucity of open-access biomarker databases does not help and there is need for better standardisation, with proof of robustness of biomarker tests in investigator-blinded, multi-institutional trials before uptake of the biomarker assay in the clinic [44]. In reporting biomarker studies, guidelines such as STARD and REMARK should be adhered to so that reliability and quality can be assessed and biomarkers compared across studies; it is clear that many studies fail to follow these guidelines [56,57]. In summary, clearly 
defining intended use, good study design, appropriate patient specimens and proper validation are critical to the success of cancer biomarker discovery efforts and in gaining regulatory approval for their clinical use.

\section{Proteomic Cancer Biomarker Discovery - Applications of MS-Based Methods}

MALDI and SELDI linked to time-of-flight (TOF) MS and capillary electrophoresis ESI MS have been used extensively in cancer biomarker discovery [58-60]. Linking these methods with robotic liquid handling for automated polypeptide extraction and sample spotting allows a rapid, high-throughput means of obtaining spectral patterns from various sample types. Using these methods, numerous studies have reported spectral patterns and multi-peak classifiers (usually comprising low-mass polypeptide species) that could accurately discriminate cancer from control biofluid specimens [61-68]. Whilst these approaches were initially heralded as a rapid and accurate means for cancer diagnoses, questions concerning their reproducibility, lack of identification of the discriminatory peaks and the robustness of the class-prediction algorithms employed have since cast doubt on the validity of some studies $[69,70]$. The lack of reproducibility is in part associated with the stability of the low-mass proteome and its sensitivity to preanalysis sample handling conditions (see above). In serum at least, the diagnostic peaks identified are chiefly fragments of abundant coagulation, complement and apolipoproteins [71], generated through the action of proteases during clotting. Whilst it has been proposed that tumour-specific exopeptidases or dysregulated haemostasis may generate these diagnostic peptide signatures [72,73], other studies have failed to find high-accuracy discriminatory signatures [74,75]. Despite this negative viewpoint, two discoveries made using SELDI- and MALDI-TOF MS have progressed to commercialised biomarker tests $[67,76]$. The OVA1 test may have clinical utility in discriminating benign from malignant pelvic masses observed by ultrasound, although notably immunoassays were ultimately used for the approved test as the reproducibility of the discovery SELDI-TOF platform was deemed inadequate for routine clinical use. The MALDI-TOF-based VeriStrat test has prognostic utility and to guide second-line therapy choice in non-small cell lung cancer.

Quantitative LC-MS/MS in DDA mode has been used extensively for profiling biofluid samples and offers a higher depth of coverage than the TOF MS-based approaches outlined above. Whilst the number of reported studies is huge, and protein coverage is ever-increasing, virtually all studies to date have failed to provide accurate cancer biomarker panels suitable for clinical use. The main reasons for this are outlined in the section above. The secretomes of engineered cell models or tumour-derived cell lines may offer a more consistent matrix for the identification of specific biomarker candidates using LC-MS/MS profiling [77-85]. In one study, mutated tryptic peptides derived from cancer-mutated proteins were identified from the secretomes of multiple colorectal cancer cell lines using a bespoke mutant protein database [79]. These mutated proteins have the potential to serve as highly specific tumour markers. Genetically engineered 
mouse models have also been used for the discovery of human cancer biomarker candidates [86]. Mouse models offer a more homogeneous genetic background and permit sampling from defined tumour stages and mutant sub-types. As the sensitivity of proteomic methods continues to increase, it is now possible to conduct high-coverage discovery studies using very small amounts of clinical material. For example, a depth of coverage of 10,000 proteins per specimen was achieved by profiling adenoma and paired colorectal cancer and adjacent normal tissue specimens obtained by laser-capture microdissection [14]. The in-depth analysis of tumour-proximal specimens, which in theory should be enriched in secreted tumour markers, is also a future direction. Examples include nipple aspirates, biliary brushings, bronchoalveolar lavage fluid and cyst fluid. Membrane-derived extracellular vesicles (exosomes) may also be an enrichable source of tumour biomarkers, with growing evidence that their protein cargoes also play a role in promoting cancer and metastasis [87]. In a recent study, MS-based profiling of cancer cell-derived exosomes identified GPC1 as an enriched protein. The investigators went on to show that GPC1+ exosomes isolated from serum could detect pancreatic cancer with absolute specificity and sensitivity [88].

Data-independent analysis (DIA) methods have been developed more recently for application in both biomarker discovery and verification [89-93]. In DIA methods, the mass spectrometer typically cycles through low and elevated fragmentation energy modes over the course of the chromatographic elution and the entire $m / z$ acquisition range (e.g., (HD)MS $\left.{ }^{\mathrm{E}}[94,95]\right)$ or through adjacent precursor isolation windows (e.g., SWATH [96]), fragmenting all precursor ions together in each elevated-energy full MS scan or isolation window. This creates a comprehensive but highly convoluted MS/MS spectral dataset that is in essence a permanent digital map of the sample analysed. Spectra are deconvoluted either by time and accurate mass matching of chromatographic profiles of precursor and fragment ions or by using high-quality spectral libraries of native or synthetic peptides obtained in DDA mode. Quantitative information can be extracted from the digital maps using spiked standards or signals from the spectral libraries. DIA methods have the potential to accelerate biomarker discovery by allowing mining of historical spectral datasets for any protein and thus to verify candidate biomarkers from other earlier studies [97].

The DIA method HDMS $^{\mathrm{E}}$ was recently used for discovery of serum markers to discriminate cholangiocarcinoma from benign biliary tract disease [98] and resectable pancreatic cancer from benign pancreatic disease [99], with reasonable coverage achieved for this difficult matrix. SWATH MS has been combined with pressure cycling technology for rapid sample dissolution and proteolysis to generate fragment ion maps of 18 biopsy samples from 9 patients with renal cell carcinoma [100]. Over 2,000 proteins were quantified from the SWATH maps and proteins were identified that could distinguish tumour from healthy tissue and discriminate histological subtypes. The same group used SWATH MS to analyse isolated $\mathrm{N}$-linked glycopeptides from normal and prostate tumour specimens, searching SWATH maps with a spectral library of known $\mathrm{N}$-glycosites [101]. 220 differentially expressed glycoproteins were identified 
and two (NAAA and PTK7) were validated as potential prognostic biomarkers by tissue microarray analysis. Similarly, lectin glycoprotein capture and SWATH MS was used to profile the secreted glycoproteome of a model cell system of metastatic colon cancer, identifying LAMB1 as a potential diagnostic marker [83]. Finally, in a study searching for tumour markers of oesophageal squamous cell carcinoma, SWATH MS was combined with MRM for discovery and verification [102]. Of 1,758 proteins quantified, 467 were differentially expressed between normal and tumour tissue with 116 verified by MRM assays which showed high correlation with the SWATH MS data. The MRM assays were then conducted in a subset of peptide library-equalized serum samples from the same patients, taken pre- and post-operatively. Although the success rate of the serum MRM assays was considerably reduced, several candidate biomarkers were verified in serum. The speed and sensitivity of new SWATH MS methods is expected to improve, allowing use of smaller isolation windows that will reduce interfering peaks and allow more reliable identification and quantification of lower abundance peptides.

\section{Cancer Biomarker Assays}

Antibody-based protein detection is the most widely used method for protein quantification and remains the gold standard for protein assays in the clinical laboratory. However, it can be limited by the availability of suitable antibodies of defined specificity. Targeted MS is an analytical technique with high specificity, reproducibility and dynamic range and methods such as SRM/MRM on triple quadrupole instruments are now used routinely for the accurate measurement of peptides and other analytes in biospecimens $[103,104]$. SRM/MRM enable the measurement of proteotypic peptides that uniquely represent the target protein of interest and make use of stable isotope-labelled standard peptides spiked into the samples for quantification. Selection of optimal transitions for MRM assays requires significant effort, although this has been partly overcome in parallel reaction monitoring on quadrupole orbitrap instruments, where all fragment ions of the target peptide ion precursor can be recorded for each charge state with selection of optimal fragment ion traces for identification and quantification carried out postacquisition [105]. In the biomarker discovery pipeline, MRM is already showing great potential as a tool for rapid verification and validation $[106,107]$ and efforts are underway to standardise its use [108]. MRM also provides the analytical depth and sensitivity for biomarker analysis from bodyfluids such as urine and saliva that can be non-invasively obtained but harbour intrinsically lower amounts of biomarkers than the tumour-proximal bodyfluids discussed in the previous section.

The parallel nature of MRM has raised the possibility that specific assays could be configured and multiplexed to measure all human proteins. In a pilot study designed to test the feasibility of large-scale, inter-laboratory efforts in this area, 645 novel MRM assays representing 319 proteins were configured and multiplexed to quantify endogenous proteins in a panel of breast cancer cell lines across three laboratories 
[109]. High inter-laboratory correlation and assay precision were reported, and peptide measurements were able to discriminate tumour subtypes and identify genome-driven changes in the cancer proteome. But are large-scale targeted approaches amenable to biomarker discovery? Targeted proteomics by its very nature relies on prior knowledge that the targeted analyte is worth measuring in the first place and this is by no means a given. In one recent study, 371 candidate lung cancer biomarkers found from MS-based tissue profiling and literature searching were assessed in a three-site discovery and validation study using MRM assays [110]. The work identified a 13-protein plasma-based classifier that could differentiate patients with malignant and benign lung nodules with high confidence. A modified version of the classifier has since been independently validated and provides a clinically useful diagnostic tool to avoid invasive biopsy on benign lung nodules [111]. It is becoming evident that combining multiple protein measurements together using multi-variate modelling approaches offers a more effective approach in determining an individual's state of health or disease.

The clinical application of MS will certainly come via its unparalleled analytical specificity. An example of this may be the assay of cancer-specific, post-translationally modified proteins, which may be more accurate biomarkers for diagnosis and prognosis [112]. However, it is as yet unclear whether targeted MSbased approaches can be used to accurately assay low-abundance biomarkers in a high-throughput fashion. Current tumour markers such as CA125, PSA and CEA are expressed at the mid-pg/mL to low-ng/mL range, below the analytical sensitivity of SRM/MRM. A way around this has been to pre-fractionate, immunodeplete, or affinity-enrich proteins prior to targeted MS analysis (see above). Affinity-enrichment is employed in so-called MS immunoassays, where a protein or peptide is first captured from the biofluid sample on immobilised antibodies prior to ESI-MS/MS or MALDI-TOF MS analysis [113-115]. This strategy has the added benefit that multiple proteoforms of the target protein can be resolved and characterised simultaneously. The methodology also lends itself to automation, facilitating rapid throughput [116]. Whilst such methods may suffer from increased technical variation compared to standard immunologic assays and will be challenging to standardise in the clinical laboratory, their use in research is becoming more widespread as reagents are developed and analytical sensitivity improves.

\section{Mass Spectrometry Imaging (MSI)}

Although mass spectrometry imaging (MSI) of biomolecules was introduced more than two decades ago its development and application was mainly focused on tissue analysis of animal models. It took the best part of two decades to develop the sample preparation and ion sources for this technology to achieve the spatial resolution, sensitivity and versatility to become a competitive imaging technique in clinical diagnostics and research. By scanning the sample with a well-focused laser beam and acquiring individual mass spectra from extremely small desorption spots, which is often called the 'microprobe' approach (see 
Figure 2), it is now possible to image lipids from tissue slices with a spatial resolution of less than $10 \mu \mathrm{m}$ and thus achieve single-cell resolution $[117,118]$. However, using smaller desorption spot (image pixel) sizes for improved spatial resolution leads to reduced sensitivity as the total number of ions generated will decrease with a smaller desorption spot. In addition, smaller image pixel sizes result in a larger number of pixels, i.e. desorption events, for a given image area and therefore an increased acquisition time, often several hours even with high-speed scanning systems and high-repetition lasers. To overcome the general problem of the relatively long analysis times in MSI there have been recent efforts in establishing the 'microscope' approach for MSI, which eliminates the need for acquiring individual mass spectra for many small pixels by employing ion optics that can image the spatial distribution of all desorbed ions to a space-sensitive detector [119].

In the context of clinical cancer research and diagnostics all of the above described issues are of relevance. For instance, cancer-specific biomolecules (markers) can be of extremely low abundance, and analysis times for intra-operative diagnostics are inherently restricted. However, there have been some important recent advances in the field of MSI and its application to cancer research and analysis. Most of these have been achieved by using MALDI as the ionisation method. Nonetheless, there are other methods suitable for MSI of biomolecules such as DESI [120], (cluster) SIMS [121], LESA [122], etc. but virtually all of these have not matured to the extent MALDI MSI has, and only a few reports have emerged using these techniques in the field of cancer research (e.g., [120]). In contrast, the more general laser desorption/ionisation (LDI), of which MALDI is a member belonging to the 'soft' ionisation sub-types, can certainly take direct advantage of most of the MALDI MSI advances and be an adequate replacement for MALDI if the analytes do not require the softness of MALDI as it is often the case for small biomolecules. In fact, in this case LDI will have the advantage not to be restricted by the cumbersome MALDI sample preparation and its effect on analyte diffusion, which can ultimately limit the achievable spatial resolution. Similarly, employing an infrared (IR) laser and exploiting native IR light-absorbing biological matrix molecules such as water for native IR-(MA)LDI can be utilised to avoid MALDI sample preparation [123]. IRas well as UV-(MA)LDI have also been used in combination with electrospray to widen the MSI tool box further, providing some of the advantages of ESI-generated ions such as higher charge states (e.g., LAESI [124], ELDI [125], IR-/UV-MALDESI [126]). In addition, the introduction of atmospheric pressure (AP) MALDI ion sources for MSI $[118,127]$ should prove to be advantageous in the future, considering the potential need for rapid clinical analysis.

Currently, the employment of MSI in cancer analysis can be roughly divided into two main areas, i.e. (MA)LDI MSI of (i) smaller biomolecules such as lipids, hormones and (drug) metabolites and (ii) proteins and proteolytic peptides. (MA)LDI MSI has been particularly powerful and well-demonstrated in mapping smaller biomolecules. Lipids but also peptidic hormones and proteins have been useful in defining tumour 
margins (cf. REIMS - see below) and (intra-)tumour heterogeneity [128-131], presenting an option for fast intra-operative decision making in surgery. Cancer drugs and their metabolites such as erlotinib [132] and irinotecan [133] have been mapped for various treatments and cancers, particularly in animal models. MALDI MSI has also been explored for the analysis of tissue microarrays to predict cancer treatment response [134]. Proteins but also lipids have been mapped by MALDI MSI to evaluate their diagnostic and in particular prognostic marker potential [135-137], for instance in differentiating and identifying invasive and metastatic cancer subtypes. In general, MSI has been unsurprisingly more applied to the analysis of common cancers such as breast cancer [134,137-139] and colon cancer $[133,135]$, but in a few cases also to rare cancers [140]. That MALDI MSI is more mature than other MSI methods can be seen by the various efforts to standardise the technology and to take the next steps to make it a clinically acceptable diagnostic method, e.g. by investigating its performance in multicentre studies [138]. Further details on MSI in cancer analysis can be found in recent focused reviews [141-143].

\section{MS-Based Cancer Analysis in the Clinic}

As mentioned in the previous section MSI is on the verge of becoming a viable option for intra-operative analysis and diagnostics. There are other MS-based technologies that are now entering the field of clinical analysis from population screening and clinical microbiology to surgery. In this section MS-based technologies are described that are directly related to clinical cancer analysis/diagnostics.

\subsection{Rapid Evaporative lonisation Mass Spectrometry (REIMS) and the 'iKnife'}

First introduced in 2009, Rapid Evaporative Ionisation Mass Spectrometry (REIMS) was demonstrated to allow the analysis of thermally evaporated ions, particularly phospholipids, from biological samples [144]. Building on a previously reported Venturi-type gas jet and polytetrafluoroethylene (PTFE) transfer line attached to the mass spectrometer inlet, analyses were performed without close proximity to the instrument [145]. An electrosurgical knife fitted to the inlet of the transfer line was used to evaporate tissue (see Figure 3), producing a cloud of molecules and clusters in the process. The applicability of the mass spectrometer being on-line but remote to the surgical site was expanded upon, particularly with regards to real-time analysis of tissue during surgery. Currently, tissue samples must be analysed in a separate laboratory during surgery. The patient remains anesthetized while analysis is performed, typically a 20-30 minute process which might require repeating. With near-instantaneous feedback by REIMS analysis there is potential for reducing surgery times, benefitting patients and hospitals alike. The comparison of tissue to library profiles with multivariate analysis allows for on-line discrimination of tissue types (e.g. healthy vs. cancerous) for highly precise and complete removal of only tumour tissue. This is 
particularly important in brain (a lipid-rich organ) surgery, where removing more healthy tissue than necessary can have dramatic effects on a patient's cognitive function.

The classification of REIMS spectral profiles of tissues by principal component analysis (PCA) was demonstrated with healthy and cancerous canine breast tissue, exploiting the fact that the phospholipid composition of cancerous cells significantly differs to that of healthy cells [146]. A comprehensive initial study of intra-operative tissue identification by REIMS confirmed its applicability to surgery [147]. Samples from 302 patients were analysed to build a tissue mass spectral profile database (1,624 cancerous and 1,309 noncancerous entries). Data from samples acquired in surgery underwent multivariate analysis with respect to this database. A total of 81 surgical samples were analysed, which also underwent postoperative histological diagnosis. A $100 \%$ of these samples matched the results from the traditional tissue identification method.

The evolution of REIMS, particularly the electrosurgical 'iKnife', has captured the attention of the broader community [148-150]. REIMS and the 'iKnife' concept has been commercialised and a research version has already hit the market $[151,152]$. An endoscopic modification to this concept has also been reported recently for the in-vivo analysis of gastrointestinal polyps. By following a similar workflow to other REIMS studies in terms of data analysis, healthy intestinal wall tissue, cancerous, and adenomatous polyps were distinguished by their REIMS spectra. Compatible with current endoscopic apparatus, this allows REIMS to be applied in a relatively less invasive process. The authors propose that this could allow for the development of an endoscopic in situ tool for bacterial analysis, since REIMS has also shown promise as a bacterial identification technique $[153,154]$.

REIMS has recently also been employed for MSI [155]. Currently, there is poor spatial resolution (approximately $500 \mu \mathrm{m}$ ) compared to MALDI MSI, which is an issue particularly for tissue with high heterogeneity. The physical probe nature of REIMS also resulted in cross-contamination of cancerous regions with healthy tissue, an issue not experienced with DESI MSI in the same article. In general, this is an inherent weakness of REIMS probes and presumably a difficult problem to solve. The usefulness of REIMS for MSI and other applications also relies on its further development to encompass additional molecule classes beyond lipids. At this early stage of development, the advantages offered by the more established MSI techniques are considerable.

\subsection{Lasers and other surgical tools as part of an MS analysis system}

The use of lasers [156] and ultrasound-based [157] surgical tools has also been explored. Lasers in particular are of interest because they remove the issues of a physical contact probe and its contamination, reducing the potential for sample carry-over. The laser approach relies on the absorption of laser energy and localised Joule heating to desorb material, a complex process when one considers the variety of 
molecules present in a biological sample. Laser energy per pulse was required to be in the order of $\mathrm{mJ}$, approximately three orders of magnitude greater than that required for MALDI MS. However, MALDI requires a matrix compound to facilitate the efficient absorption of the laser's energy, but this is not compatible with an in-vivo approach to sampling.

\subsection{MS biotyping}

A very recent example where MS has been revolutionary in clinical analysis can be found in the area of clinical microbiology [158]. Comprehensive MALDI MS-based analytical systems have been introduced to the clinical microbiology in-vitro diagnostics (IVD) market and achieved CE (Conformité Européenne)-IVD certification and FDA (US Food and Drug Administration) approval as medical devices. These systems have been primarily used to biotype (analyse/identify) microorganisms in a typica/ clinical microbiology setting. As such there have been only a few studies where their potential use in cancer analysis has been investigated such as in bacterial infections that are linked to higher cancer incidences. For instance, a recent study has investigated the identification capability of these systems for Helicobacter pylori, which is a Gram-negative, microaerophilic bacterium found in the stomach and associated with gastric cancer for specific genotypes [159].

\section{Outlook and Conclusion}

Although mass spectrometry has been a major tool for decades in clinical research, analysis and diagnostics (e.g. LC-MS/MS in new-born screening), its application to oncology and clinical cancer analysis in general has just begun. Certainly, the long-established clinical mass spectrometry methods are also applicable to cancer as one of the many diseases modern healthcare has to cope with, but in many cases their applicability is limited to the intricacies and complexity of cancer, as well as the low abundance of the cancer-specific protagonists whose detection and identification could lead to new therapies and diagnostics.

While classical mass spectrometry and its advances in sensitivity, quantitation and throughput are extremely helpful in analysing cancer-specific low-abundant target molecules (e.g. in cancer proteomics) and thus the backbone of MS-based cancer research and analysis, many of the new MS-based methods now entering the clinic exploit new concepts in MS analysis such as mass spectral profiling (e.g. biotyping) and MSI. In these areas further advances can be expected, in particular with respect to data mining software and databases and technological improvements such as space-sensitive ion detection for 'microscope' approaches in MSI.

In general, mass spectrometry has also the advantage to be able to cater for extremely different types of clinical diagnosis, e.g., the more population-wide early diagnosis of disease through screening tests and the 
highly individualised care in precision medicine and individual treatment such as surgery. Both are of utmost importance in cancer diagnosis and treatment as early accurate cancer detection still provides the best prognosis for patients due to more effective interventions at an early stage, while cancer therapy and surgery can also greatly benefit from the power of MS in providing rapid analyses of a patient's molecular profiles, thus enabling accurate and fast treatment decisions for the individual patient.

New approaches afforded by MS such as screening - possibly of MS-identified and validated biomarkers, but ultimately measured by other means such as immunological assays -, MSI-based pharmacokinetics and pathology or precision surgery using an 'iKnife' will be invaluable in future cancer research and analysis. However, there is still room for improvement for all of the new approaches: for instance, greater analyte range in REIMS, faster data acquisition and a more physiological sample environment in MSI, better validation of MS-identified biomarkers, and of course, higher sensitivity and quantitation accuracy in all cases. Nonetheless, these new approaches have provided another recent wave of adyances in clinical mass spectrometry with cancer research and analysis the areas benefitting the most.

Encouragingly, there are even more new approaches in the pipeline such as mass cytometry combined with large-scale data mining, another promising MS-based analytical method for precision medicine (prognostics) and recently applied to phenotyping of single acute myeloid leukemia cells [160]. Another new early-stage approach is MS profiling of breath biomarkers using one of the easiest and least invasive sampling of patient-generated biomolecules [161-164]. Thus, it seems that clinical mass spectrometry has firmly established itself as a game changer for cancer research and analysis in the years to come.

\section{Expert commentary}

Recent years have seen significant improvements in MS instrument speed, sensitivity, mass accuracy and resolution. Because of these advances, LC-MS profiling in discovery mode can now provide near wholegenome coverage of cancer proteomes in relevant cell models and tissue specimens, allowing the detailed characterisation of protein expression, mutational status and post-translational modifications. As such, MSbased protein profiling when combined with genomic, transcriptomic and metabolite profiling is revealing the molecular mechanisms and biological processes that contribute to cellular transformation and tumour progression at an unprecedented level of molecular detail. Hitherto unknown mechanisms in cancer biology are now being elucidated which will hopefully drive the development of novel anti-cancer therapies. Moreover, this work is identifying protein changes in patient tissue specimens and biofluids that may serve as potential cancer biomarkers. The onus is now on researchers to validate these findings. Despite the perceived failure of proteomics to deliver biomarkers with clinical utility, examples of approved tests provided in this review show that this is not the case and there is hope that MS-based approaches will continue to deliver. However, the learning curve of biomarker discovery must be surmounted before 
success can be achieved. Problems with study design, sample choice and lack of validation are still major issues in many studies. Combining panels of markers using novel mathematical approaches has been shown to improve test performances and lends itself to a personalised approach to cancer diagnosis, prognosis and therapy choice. The development of rapid MS-based assays capable of very precisely identifying and quantifying proteotypic peptide ions, and allowing the detailed chemical characterisation of distinct proteoforms with biomarker potential is beginning to circumvent the need for immunological assays, where specificity is not guaranteed. However, analytical sensitivity must be improved before MS-based assays can replace immunoassays for accurate quantification of protein biomarkers in complex matrices. Tests must be appropriately validated in multicentre, prospective trials and shown to outperform the gold standard tests before they can be considered for uptake in the clinic. The challenge will then be to make such tests technically robust, easy to run and high-throughput for the clinical laboratory

Beyond the areas and issues related to MS-based cancer biomarker discovery and assay development there are other fields and opportunities opening up for mass spectrometry to become an important tool in cancer analysis, in particular as a diagnostic tool in clinical laboratories and even within the operating theatre. The former has already been proven to be a game changer in clinical microbiology, quickly achieving the status of a fully approved medical device, while the latter has now gone beyond the proof-of-principle stage. These are just two more examples where MS has demonstrated its analytical superiority in speed, specificity and breadth of (untargeted) analysis. All these characteristics will further advance its place in clinical cancer research and analysis.

\section{Five-year view}

In the next five years further advances in both the MS-based technologies and their applications will certainly feed through to cancer-related research and clinical applications. New putative biomarkers or biomarker panels (and their screening potential in combination with or without established and future nonMS screening modalities) will be found and the prospect of MS-based clinical diagnostics and prognostics will further excite the field. However, five years is a short time frame for any major changes in the clinical arena. Thus, how far new cancer biomarkers or IVD devices developed with the help of MS will be validated and approved in this time frame remains to be seen. In this context it is important to note that the introduction of new medical devices and tests has to undergo a stringent approval process and therefore any progress in utilizing MS-based discoveries or technologies in oncology are difficult to predict. Progress will highly depend on the quality of the supporting data and its acquisition, the potential in improving diagnostic accuracy and speed and, last but not least, the willingness to embrace new technology in the clinic. 


\section{Key Issues}

- Mass spectrometry (MS)-based cancer proteomics and metabolomics have continued to evolve and mature for biomarker discovery.

- Limitations and problems with study design, sample choice and lack of validation have hindered the adoption of these into the clinical setting.

- Established MS methods, including MALDI-TOF MS, SELDI-TOF MS, LC-ESI MS/MS have all found utility.

- The use of new Data-Independent Analysis (DIA) methods, e.g. HDMS ${ }^{\mathrm{E}}$, SWATH opens up further avenues of investigation.

- Laser desorption MS techniques such as MALDI Mass Spectrometry Imaging (MSI) are increasingly found in cancer research and analysis.

- Novel techniques such as REIMS and biotyping continue to demonstrate the evolution of mass spectrometry for clinical applications.

\section{Declaration of interest}

$R$ Cramer is supported in part by Waters Corporation. JF Timms is supported by the National Institute for Health Research University College London Hospitals Biomedical Research Centre. OJ Hale is supported through a studentship funded by the EPSRC and Waters Corporation. The authors have no other relevant affiliations or financial involvement with any organization or entity with a financial interest in or financial conflict with the subject matter or materials discussed in the manuscript apart from those disclosed. 


\section{References}

Papers of special note have been highlighted as:

* of interest

** of considerable interest

1. Cox J, Mann M. Quantitative, high-resolution proteomics for data-driven systems biology. Annu Rev Biochem, 80, 273-299 (2011).

2. Altelaar AF, Heck AJ. Trends in ultrasensitive proteomics. Current opinion in chemical biology, 16(12), 206-213 (2012).

3. Smith LM, Kelleher NL. Proteoform: a single term describing protein complexity. Nat Methods, 10(3), 186-187 (2013).

4. Motoyama A, Yates JR, 3rd. Multidimensional LC separations in shotgun proteomics. Analytical chemistry, 80(19), 7187-7193 (2008).

5. Ntai I, LeDuc RD, Fellers RT et al. Integrated Bottom-Up and Top-Down Proteomics of PatientDerived Breast Tumor Xenografts. Molecular \& cellular proteomics : MCP, 15(1), 45-56 (2016).

6. Timms JF, Cutillas PR. Overview of quantitative LC-MS techniques for proteomics and activitomics. Methods in molecular biology, 658, 19-45 (2010).

7. Silva JC, Denny R, Dorschel CA et al. Quantitative proteomic analysis by accurate mass retention time pairs. Analytical chemistry, 77(7), 2187-2200 (2005).

8. Thompson A, Schafer J, Kuhn K et al. Tandem mass tags: a novel quantification strategy for comparative analysis of complex protein mixtures by MS/MS. Analytical chemistry, 75(8), 18951904 (2003).

9. Ross PL, Huang XN, Marchese JN et al. Multiplexed protein quantitation in Saccharomyces cerevisiae using amine-reactive isobaric tagging reagents. Molecular \& cellular proteomics : MCP, $3(12), 1154-1169$ (2004).

10. Hsu JL, Huang SY, Chow NH, Chen SH. Stable-isotope dimethyl labeling for quantitative proteomics. Analytical chemistry, 75(24), 6843-6852 (2003).

11. Ong SE, Blagoev B, Kratchmarova I et al. Stable isotope labeling by amino acids in cell culture, SILAC, as a simple and accurate approach to expression proteomics. Molecular \& cellular proteomics : MCP, 1(5), 376-386. (2002).

12. Geiger T, Cox J, Ostasiewicz P, Wisniewski JR, Mann M. Super-SILAC mix for quantitative proteomics of human tumor tissue. Nat Methods, 7(5), 383-385 (2010). 
13. Iglesias-Gato D, Wikstrom P, Tyanova S et al. The Proteome of Primary Prostate Cancer. Eur Urol, (2015).

* A study reporting a system-wide quantitative analysis of proteome changes associated with localised prostate cancer and the identification of a potential prognostic marker.

14. Wisniewski JR, Dus-Szachniewicz K, Ostasiewicz P, Ziolkowski P, Rakus D, Mann M. Absolute Proteome Analysis of Colorectal Mucosa, Adenoma, and Cancer Reveals Drastic Changes in Fatty Acid Metabolism and Plasma Membrane Transporters. Journal of proteome research, 14(9), 4005 4018 (2015).

** An impressive coverage of 10,000 proteins per patient from microdissected formalin-fixed paraffinembedded normal, adenoma and colorectal cancer tissue.

15. Bischoff R, Permentier H, Guryev V, Horvatovich P. Genomic variability and protein species Improving sequence coverage for proteogenomics. Journal of proteomics, (2015).

16. Menschaert G, Fenyo D. Proteogenomics from a bioinformatics angle: A growing field. Mass spectrometry reviews, (2015).

17. Zhang B, Wang J, Wang $X$ et al. Proteogenomic characterization of human colon and rectal cancer. Nature, 513(7518), 382-387 (2014).

** A commendable example of the proteogenomic and proteotranscriptomic profiling of 95 colorectal tumours reporting proteomic, transcriptomic and genetic subtypes and their associations.

18. Jmeian Y, El Rassi Z. Liquid-phase-based separation systems for depletion, prefractionation and enrichment of proteins in biological fluids for in-depth proteomics analysis. Electrophoresis, 30(1), 249-261 (2009).

19. Righetti PG, Boschetti E, Lomas L, Citterio A. Protein Equalizer Technology : the quest for a "democratic proteome". Proteomics, 6(14), 3980-3992 (2006).

20. Yang ZP, Hancock WS. Monitoring glycosylation pattern changes of glycoproteins using multi-lectin affinity chromatography. Journal of Chromatography A, 1070(1-2), 57-64 (2005).

21. Engholm-Keller K, Larsen MR. Titanium dioxide as chemo-affinity chromatographic sorbent of biomolecular compounds--applications in acidic modification-specific proteomics. Journal of proteomics, 75(2), 317-328 (2011).

22. Selvaraju S, Rassi ZE. Liquid-phase-based separation systems for depletion, prefractionation and enrichment of proteins in biological fluids and matrices for in-depth proteomics analysis--an update covering the period 2008-2011. Electrophoresis, 33(1), 74-88 (2012).

23. Puangpila C, Mayadunne E, El Rassi Z. Liquid phase based separation systems for depletion, prefractionation, and enrichment of proteins in biological fluids and matrices for in-depth 
proteomics analysis-An update covering the period 2011-2014. Electrophoresis, 36(1), 238-252 (2015).

24. Britton D, Zen Y, Quaglia A et al. Quantification of pancreatic cancer proteome and phosphorylome: indicates molecular events likely contributing to cancer and activity of drug targets. Plos One, 9(3), e90948 (2014).

25. Wilkes EH, Terfve C, Gribben JG, Saez-Rodriguez J, Cutillas PR. Empirical inference of circuitry and plasticity in a kinase signaling network. Proceedings of the National Academy of Sciences of the United States of America, 112(25), 7719-7724 (2015).

** A systematic characterisation of the topology and dynamics of kinase signalling networks in response to growth factor triggering and chemical inhibition using phosphoproteomics.

26. Zhao J, Simeone DM, Heidt D, Anderson MA, Lubman DM. Comparative serum glycoproteomics using lectin selected sialic acid glycoproteins with mass spectrometric analysis: application to pancreatic cancer serum. Journal of proteome research, 5(7), 1792-1802 (2006).

27. Zeng $\mathrm{X}$, Hood $\mathrm{BL}$, Sun $\mathrm{M}$ et al. Lung cancer serum biomarker discovery using glycoprotein capture and liquid chromatography mass spectrometry. Journal of proteome research, 9(12), 6440-6449 (2010).

28. Chen J, Xi J, Tian Y, Bova GS, Zhang H. Identification, prioritization, and evaluation of glycoproteins for aggressive prostate cancer using quantitative glycoproteomics and antibody-based assays on tissue specimens. Proteomics, 13(15), 2268-2277 (2013).

29. Deeb SJ, Cox J, Schmidt-Supprian M, Mann M. N-linked glycosylation enrichment for in-depth cell surface proteomics of diffuse large B-cell lymphoma subtypes. Molecular \& cellular proteomics : MCP, 13(1), 240-251 (2014).

30. Findeisen $P$, Neumaier $M$. Functional protease profiling for diagnosis of malignant disease. Proteomics Clin Appl, 6(1-2), 60-78 (2012).

31. Hunt DF, Henderson RA, Shabanowitz J et al. Characterization of peptides bound to the class I MHC molecule HLA-A2.1 by mass spectrometry. Science, 255(5049), 1261-1263 (1992).

32. Caron E, Kowalewski DJ, Chiek Koh C, Sturm T, Schuster H, Aebersold R. Analysis of Major Histocompatibility Complex (MHC) Immunopeptidomes Using Mass Spectrometry. Molecular \& cellular proteomics : MCP, 14(12), 3105-3117 (2015).

33. Berlin C, Kowalewski DJ, Schuster $\mathrm{H}$ et al. Mapping the HLA ligandome landscape of acute myeloid leukemia: a targeted approach toward peptide-based immunotherapy. Leukemia, 29(3), 647-659 (2015).

* An immunoproteomics approach identifying over 25,000 HLA-presented peptides on AML and healthy mononuclear cells with functional characterisation of cancer-associated peptides. 
34. Couzin-Frankel J. Breakthrough of the year 2013. Cancer immunotherapy. Science, 342(6165), 14321433 (2013).

35. Gika HG, Wilson ID, Theodoridis GA. LC-MS-based holistic metabolic profiling. Problems, limitations, advantages, and future perspectives. J Chromatogr B Analyt Technol Biomed Life Sci, 966, 1-6 (2014).

36. Sreekumar A, Poisson LM, Rajendiran TM et al. Metabolomic profiles delineate potential role for sarcosine in prostate cancer progression. Nature, 457(7231), 910-914 (2009).

37. Ritchie SA, Akita H, Takemasa I et al. Metabolic system alterations in pancreatic cancer patient serum: potential for early detection. BMC Cancer, 13, 416 (2013).

38. Losman JA, Looper RE, Koivunen P et al. (R)-2-hydroxyglutarate is sufficient to promote leukemogenesis and its effects are reversible. Science, 339(6127), 1621-1625 (2013).

39. Wang H, Shi T, Qian WJ et al. The clinical impact of recent advances in LC-MS for cancer biomarker discovery and verification. Expert review of proteomics, 13(1), 99-114 (2016).

40. Flatley B, Malone P, Cramer R. MALDI mass spectrometry in prostate cancer biomarker discovery. Biochimica et biophysica acta, 1844(5), 940-949 (2014).

41. Indovina P, Marcelli E, Pentimalli F, Tanganelli P, Tarro G, Giordano A. Mass spectrometry-based proteomics: the road to lung cancer biomarker discovery. Mass spectrometry reviews, 32(2), 129142 (2013).

42. Timms JF, Menon U, Devetyarov D et al. Early Detection of Ovarian Cancer in Samples Pre-Diagnosis Using CA125 and MALDI-MS Peaks. Cancer genomics \& proteomics, 8(6), 289-305 (2011).

43. Tiss A, Timms JF, Smith C et al. Highly accurate detection of ovarian cancer using CA125 but limited improvement with serum matrix-assisted laser desorption/ionization time-of-flight mass spectrometry profiling. International journal of gynecological cancer : official journal of the International Gynecological Cancer Society, 20(9), 1518-1524 (2010).

44. Ludwig JA, Weinstein JN. Biomarkers in cancer staging, prognosis and treatment selection. Nat Rev Cancer, 5(11), 845-856 (2005).

45. Banks RE, Stanley AJ, Cairns DA et al. Influences of blood sample processing on low-molecularweight proteome identified by surface-enhanced laser desorption/ionization mass spectrometry. Clin Chem, 51(9), 1637-1649 (2005).

46. Findeisen P, Sismanidis D, Riedl M, Costina V, Neumaier M. Preanalytical impact of sample handling on proteome profiling experiments with matrix-assisted laser desorption/ionization time-of-flight mass spectrometry. Clin Chem, 51(12), 2409-2411 (2005). 
47. Diamandis EP. Serum proteomic profiling by matrix-assisted laser desorption-ionization time-offlight mass spectrometry for cancer diagnosis: next steps. Cancer research, 66(11), 5540-5541 (2006).

48. Timms JF, Arslan-Low E, Gentry-Maharaj A et al. Preanalytic influence of sample handling on SELDITOF serum protein profiles. Clin Chem, 53(4), 645-656 (2007).

49. Tuck MK, Chan DW, Chia D et al. Standard operating procedures for serum and plasma collection: early detection research network consensus statement standard operating procedure integration working group. Journal of proteome research, 8(1), 113-117 (2009).

50. Tiss A, Smith C, Camuzeaux S et al. Serum peptide profiling using MALDI mass spectrometry: avoiding the pitfalls of coated magnetic beads using well-established ZipTip technology.

Proteomics, 7 Suppl 1, 77-89 (2007).

51. Mustafa D, Kros JM, Luider T. Combining laser capture microdissection and proteomics techniques. Methods in molecular biology, 428, 159-178 (2008).

52. Gustafsson OJ, Arentz G, Hoffmann P. Proteomic developments in the analysis of formalin-fixed tissue. Biochimica et biophysica acta, 1854(6), 559-580 (2015).

53. Tonack $\mathrm{S}$, Jenkinson $\mathrm{C}, \mathrm{Cox} \mathrm{T}$ et al. iTRAQ reveals candidate pancreatic cancer serum biomarkers: influence of obstructive jaundice on their performance. Br J Cancer, 108(9), 1846-1853 (2013).

54. Tonry CL, Doherty D, O'Shea C et al. Discovery and Longitudinal Evaluation of Candidate Protein Biomarkers for Disease Recurrence in Prostate Cancer. Journal of proteome research, 14(7), 27692783 (2015).

55. Jenkinson C, Elliott V, Evans A et al. Decreased serum thrombospondin-1 levels in pancreatic cancer patients up to 24 months prior to clinical diagnosis: association with diabetes mellitus. Clin Cancer Res, (2015).

56. Mallett S, Timmer A, Sauerbrei W, Altman DG. Reporting of prognostic studies of tumour markers: a review of published articles in relation to REMARK guidelines. Br J Cancer, 102(1), 173-180 (2010).

57. Glasziou $P$, Altman DG, Bossuyt $P$ et al. Reducing waste from incomplete or unusable reports of biomedical research. Lancet, 383(9913), 267-276 (2014).

58. Petricoin EF, Liotta LA. SELDI-TOF-based serum proteomic pattern diagnostics for early detection of cancer. Curr Opin Biotechnol, 15(1), 24-30 (2004).

59. Hortin GL. The MALDI-TOF mass spectrometric view of the plasma proteome and peptidome. Clin Chem, 52(7), 1223-1237 (2006).

60. Albalat A, Husi H, Stalmach A, Schanstra JP, Mischak H. Classical MALDI-MS versus CE-based ESI-MS proteomic profiling in urine for clinical applications. Bioanalysis, 6(2), 247-266 (2014). 
61. Petricoin EF, Ardekani AM, Hitt BA et al. Use of proteomic patterns in serum to identify ovarian cancer. Lancet, 359(9306), 572-577 (2002).

62. Li J, Zhang Z, Rosenzweig J, Wang YY, Chan DW. Proteomics and bioinformatics approaches for identification of serum biomarkers to detect breast cancer. Clin Chem, 48(8), 1296-1304 (2002).

63. Poon TC, Yip TT, Chan AT et al. Comprehensive proteomic profiling identifies serum proteomic signatures for detection of hepatocellular carcinoma and its subtypes. Clin Chem, 49(5), 752-760 (2003).

64. Mobley JA, Lam YW, Lau KM et al. Monitoring the serological proteome: the latest modality in prostate cancer detection. J Urol, 172(1), 331-337 (2004).

65. Theodorescu D, Wittke S, Ross MM et al. Discovery and validation of new protein biomarkers for urothelial cancer: a prospective analysis. Lancet Oncol, 7(3), 230-240 (2006).

66. Zhang X, Wang B, Zhang XS, Li ZM, Guan ZZ, Jiang WQ. Serum diagnosis of diffuse large B-cell lymphomas and further identification of response to therapy using SELDI-TOF-MS and tree analysis patterning. BMC Cancer, 7, 235 (2007).

67. Taguchi F, Solomon B, Gregorc V et al. Mass spectrometry to classify non-small-cell lung cancer patients for clinical outcome after treatment with epidermal growth factor receptor tyrosine kinase inhibitors: a multicohort cross-institutional study. J Natl Cancer Inst, 99(11), 838-846 (2007).

68. Metzger J, Negm AA, Plentz RR et al. Urine proteomic analysis differentiates cholangiocarcinoma from primary sclerosing cholangitis and other benign biliary disorders. Gut, 62(1), 122-130 (2013).

69. Diamandis EP. Analysis of serum proteomic patterns for early cancer diagnosis: drawing attention to potential problems. J Natt Cancer inst, 96(5), 353-356 (2004).

70. Baggerly KA, Morris JS, Edmonson SR, Coombes KR. Signal in noise: evaluating reported reproducibility of serum proteomic tests for ovarian cancer. J Nat/ Cancer Inst, 97(4), 307-309 (2005).

71. Tiss A, Smith C, Menon U, Jacobs I, Timms JF, Cramer R. A well-characterised peak identification list of MALDI MS profile peaks for human blood serum. Proteomics, 10(18), 3388-3392 (2010).

72. Villanueva J, Shaffer DR, Philip J et al. Differential exoprotease activities confer tumor-specific serum peptidome patterns. J Clin Invest, 116(1), 271-284 (2006).

73. Davis MT, Auger P, Spahr C, Patterson SD. Cancer biomarker discovery via low molecular weight serum proteome profiling - Where is the tumor? Proteomics Clin Appl, 1(12), 1545-1558 (2007).

74. Skytt A, Thysell E, Stattin P, Stenman UH, Antti H, Wikstrom P. SELDI-TOF MS versus prostate specific antigen analysis of prospective plasma samples in a nested case-control study of prostate cancer. Int J Cancer, 121(3), 615-620 (2007). 
75. Timms JF, Cramer R, Camuzeaux S et al. Peptides generated ex vivo from serum proteins by tumorspecific exopeptidases are not useful biomarkers in ovarian cancer. Clin Chem, 56(2), 262-271 (2010).

76. Zhang Z, Bast RC, Jr., Yu Y et al. Three biomarkers identified from serum proteomic analysis for the detection of early stage ovarian cancer. Cancer research, 64(16), 5882-5890 (2004).

77. Sardana G, Jung K, Stephan C, Diamandis EP. Proteomic analysis of conditioned media from the PC3, LNCaP, and 22Rv1 prostate cancer cell lines: discovery and validation of candidate prostate cancer biomarkers. Journal of proteome research, 7(8), 3329-3338 (2008).

78. Sinclair J, Metodieva G, Dafou D, Gayther SA, Timms JF. Profiling signatures of ovarian cancer tumour suppression using 2D-DIGE and 2D-LC-MS/MS with tandem mass tagging. Journal of proteomics, 74(4), 451-465 (2011).

79. Mathivanan S, Ji H, Tauro BJ, Chen YS, Simpson RJ. Identifying mutated proteins secreted by colon cancer cell lines using mass spectrometry. Journal of proteomics, 76 Spec No., 141-149 (2012).

* A proteogenomics strategy was used to identify secreted and mutated proteins from colorectal cancer cell lines providing a tool for the potential identification of highly specific cancer biomarkers.

80. Zawadzka AM, Schilling B, Cusack MP et al. Phosphoprotein secretome of tumor cells as a source of candidates for breast cancer biomarkers in plasma. Molecular \& cellular proteomics : MCP, 13(4), 1034-1049 (2014).

81. Karagiannis GS, Pavlou MP, Saraon P et al. In-depth proteomic delineation of the colorectal cancer exoproteome: Mechanistic insight and identification of potential biomarkers. Journal of proteomics, 103, 121-136 (2014).

82. Teng PN, Wang G, Hood BL et al. Identification of candidate circulating cisplatin-resistant biomarkers from epithelial ovarian carcinoma cell secretomes. Br J Cancer, 110(1), 123-132 (2014).

83. Lin Q, Lim HS, Lin HL et al. Analysis of colorectal cancer glyco-secretome identifies laminin beta-1 (LAMB1) as a potential serological biomarker for colorectal cancer. Proteomics, (2015).

84. Barderas $\mathrm{R}$, Mendes $\mathrm{M}$, Torres $\mathrm{S}$ et al. In-depth characterization of the secretome of colorectal cancer metastatic cells identifies key proteins in cell adhesion, migration, and invasion. Molecular \& cellular proteomics : MCP, 12(6), 1602-1620 (2013).

85. Lawrenson K, Mhawech-Fauceglia P, Worthington J et al. Identification of novel candidate biomarkers of epithelial ovarian cancer by profiling the Secretomes of three-dimensional genetic models of ovarian carcinogenesis. Int J Cancer, (2014).

86. Faca VM, Song KS, Wang $\mathrm{H}$ et al. A mouse to human search for plasma proteome changes associated with pancreatic tumor development. PLoS Med, 5(6), e123 (2008). 
* This study describes the profiling of 1,442 plasma proteins from a well-characterised mouse model of pancreatic cancer for identification of candidate markers applicable to human cancer.

87. Greening DW, Gopal SK, Mathias RA et al. Emerging roles of exosomes during epithelialmesenchymal transition and cancer progression. Semin Cell Dev Biol, 40, 60-71 (2015).

88. Melo SA, Luecke LB, Kahlert C et al. Glypican-1 identifies cancer exosomes and detects early pancreatic cancer. Nature, 523(7559), 177-182 (2015).

89. Purvine S, Eppel JT, Yi EC, Goodlett DR. Shotgun collision-induced dissociation of peptides using a time of flight mass analyzer. Proteomics, 3(6), 847-850 (2003).

90. Venable JD, Dong MQ, Wohlschlegel J, Dillin A, Yates JR. Automated approach for quantitative analysis of complex peptide mixtures from tandem mass spectra. Nat Methods, 1(1), 39-45 (2004).

91. Chakraborty AB, Berger SJ, Gebler JC. Use of an integrated MS--multiplexed MS/MS data acquisition strategy for high-coverage peptide mapping studies. Rapid communications in mass spectrometry : $R C M, 21(5), 730-744$ (2007).

92. Gillet LC, Navarro P, Tate S et al. Targeted data extraction of the MS/MS spectra generated by dataindependent acquisition: a new concept for consistent and accurate proteome analysis. Molecular \& cellular proteomics : MCP, 11(6), 0111016717 (2012).

93. Law KP, Lim YP. Recent advances in mass spectrometry: data independent analysis and hyper reaction monitoring. Expert review of proteomics, 10(6), 551-566 (2013).

94. Li GZ, Vissers JP, Silva JC, Golick D, Gorenstein MV, Geromanos SJ. Database searching and accounting of multiplexed precursor and product ion spectra from the data independent analysis of simple and complex peptide mixtures. Proteomics, 9(6), 1696-1719 (2009).

95. Silva JC, Gorenstein MV, Li GZ, Vissers JP, Geromanos SJ. Absolute quantification of proteins by LCMSE: a virtue of parallel MS acquisition. Molecular \& cellular proteomics : MCP, 5(1), 144-156 (2006).

96. Liu Y, Huttenhain R, Collins B, Aebersold R. Mass spectrometric protein maps for biomarker discovery and clinical research. Expert review of molecular diagnostics, 13(8), 811-825 (2013).

97. Sajic T, Liu Y, Aebersold R. Using data-independent, high-resolution mass spectrometry in protein biomarker research: perspectives and clinical applications. Proteomics Clin Appl, 9(3-4), 307-321 (2015).

98. Janvilisri T, Leelawat K, Roytrakul S, Paemanee A, Tohtong R. Novel Serum Biomarkers to Differentiate Cholangiocarcinoma from Benign Biliary Tract Diseases Using a Proteomic Approach. Dis Markers, 2015, 105358 (2015).

99. Ansari D, Andersson R, Bauden MP et al. Protein deep sequencing applied to biobank samples from patients with pancreatic cancer. J Cancer Res Clin Oncol, 141(2), 369-380 (2015). 
100. Guo T, Kouvonen P, Koh CC et al. Rapid mass spectrometric conversion of tissue biopsy samples into permanent quantitative digital proteome maps. Nat Med, 21(4), 407-413 (2015).

*A good example of SWATH MS technology applied for the profiling of normal and renal cell carcinoma biopsy samples.

101. Liu Y, Chen J, Sethi A et al. Glycoproteomic analysis of prostate cancer tissues by SWATH mass spectrometry discovers $\mathrm{N}$-acylethanolamine acid amidase and protein tyrosine kinase 7 as signatures for tumor aggressiveness. Molecular \& Cellular Proteomics, 13(7), 1753-1768 (2014).

102. Hou G, Lou X, Sun Y et al. Biomarker Discovery and Verification of Esophageal Squamous Cell Carcinoma Using Integration of SWATH/MRM. Journal of Proteome Research, 14(9), 3793-3803 (2015).

103. Picotti P, Aebersold R. Selected reaction monitoring-based proteomics: Workflows, potential, pitfalls and future directions. Nature Methods, 9(6), 555-566 (2012).

104. Gallien S, Bourmaud A, Kim SY, Domon B. Technical considerations for large-scale parallel reaction monitoring analysis. Journal of Proteomics, 100, 147-159 (2014).

105. Peterson AC, Russell JD, Bailey DJ, Westphall MS, Coon JJ. Parallel reaction monitoring for high resolution and high mass accuracy quantitative, targeted proteomics. Molecular \& Cellular Proteomics, 11(11), 1475-1488 (2012).

* First report of the performance of parallel reaction monitoring on a quadrupole-equipped orbitrap MS and comparison with SRM.

106. Tang HY, Beer LA, Tanyi JL, Zhang R, Liu Q, Speicher DW. Protein isoform-specific validation defines multiple chloride intracellular channel and tropomyosin isoforms as serological biomarkers of ovarian cancer. Journal of Proteomics, 89, 165-178 (2013).

107. Ohmine K, Kawaguchi K, Ohtsuki S et al. Quantitative Targeted Proteomics of Pancreatic Cancer: Deoxycytidine Kinase Protein Level Correlates to Progression-Free Survival of Patients Receiving Gemcitabine Treatment. Molecular Pharmaceutics, 12(9), 3282-3291 (2015).

108. Rodriguez $\mathrm{H}$, Rivers $\mathrm{R}$, Kinsinger $\mathrm{C}$ et al. Reconstructing the pipeline by introducing multiplexed multiple reaction monitoring mass spectrometry for cancer biomarker verification: an NCI-CPTC initiative perspective. Proteomics Clinical Applications, 4(12), 904-914 (2010).

109. Kennedy JJ, Abbatiello SE, Kim K et al. Demonstrating the feasibility of large-scale development of standardized assays to quantify human proteins. Nature Methods, 11(2), 149-155 (2014).

110. Li XJ, Hayward C, Fong PY et al. A blood-based proteomic classifier for the molecular characterization of pulmonary nodules. Science Translational Medicine, 5(207), 207ra142 (2013). 
* A rare example of a proteomics-derived and validated plasma classifier (using MRM) that differentiates malignant and benign lung nodules and provides a complementary tool to help physicians in lung cancer diagnosis.

111. Vachani A, Hammoud Z, Springmeyer S et al. Clinical Utility of a Plasma Protein Classifier for Indeterminate Lung Nodules. Lung, 193(6), 1023-1027 (2015).

112. Li QK, Chen L, Ao MH et al. Serum fucosylated prostate-specific antigen (PSA) improves the differentiation of aggressive from non-aggressive prostate cancers. Theranostics, 5(3), 267-276 (2015).

113. Kiernan UA, Tubbs KA, Gruber K et al. High-throughput protein characterization using mass spectrometric immunoassay. Analytical Biochemistry, 301(1), 49-56 (2002).

114. Anderson NL, Anderson NG, Haines LR, Hardie DB, Olafson RW, Pearson TW. Mass spectrometric quantitation of peptides and proteins using Stable Isotope Standards and Capture by Anti-Peptide Antibodies (SISCAPA). Journal of Proteome Research, 3(2), 235-244 (2004).

115. Weiss F, van den Berg BH, Planatscher H, Pynn CJ, Joos TO, Poetz O. Catch and measure-mass spectrometry-based immunoassays in biomarker research. Biochimica et Biophysica Acta, 1844(5), 927-932 (2014).

116. Oran PE, Trenchevska O, Nedelkov D et al. Parallel workflow for high-throughput $(>1,000$ samples/day) quantitative analysis of human insulin-like growth factor 1 using mass spectrometric immunoassay. Plos One, 9(3), e92801 (2014).

117. Schober $Y$, Guenther $S$, Spengler B, Rompp A. Single cell matrix-assisted laser desorption/ionization mass spectrometry imaging. Analytical chemistry, 84(15), 6293-6297 (2012).

** One of the highest spatial resolutions $(7 \mu \mathrm{m})$ in classical MALDI MSI is reported, allowing single-cell MALDI MSI.

118. Rompp A, Guenther S, Schober $Y$ et al. Histology by mass spectrometry: label-free tissue characterization obtained from high-accuracy bioanalytical imaging. Angewandte Chemie International Edition, 49(22), 3834-3838 (2010).

119. Jungmann JH, Smith DF, MacAleese L, Klinkert I, Visser J, Heeren RM. Biological tissue imaging with a position and time sensitive pixelated detector. Journal of the American Society for Mass Spectrometry, 23(10), 1679-1688 (2012).

* A powerful demonstration of new MSI detector technology to enable microscope MSI at high performance with a spatial resolving power of $6 \mu \mathrm{m}$.

120. Jarmusch AK, Pirro V, Baird Z, Hattab EM, Cohen-Gadol AA, Cooks RG. Lipid and metabolite profiles of human brain tumors by desorption electrospray ionization-MS. Proceedings of the National Academy of Sciences of the United States of America, (2016). 
* An excellent example for the use of DESI MSI and multivariate statistics in brain tumour analysis, providing high sensitivity and specificity in distinguishing different tumour tissue types and nontumour tissue with the potential to be used as a tool for intraoperative diagnostics.

121. Fletcher JS, Vickerman JC, Winograd N. Label free biochemical 2D and 3D imaging using secondary ion mass spectrometry. Current Opinion in Chemical Biology, 15(5), 733-740 (2011).

122. Eikel D, Vavrek M, Smith S et al. Liquid extraction surface analysis mass spectrometry (LESA-MS) as a novel profiling tool for drug distribution and metabolism analysis: the terfenadine example. Rapid Communications in Mass Spectrometry : RCM, 25(23), 3587-3596 (2011).

123. Li Y, Shrestha B, Vertes A. Atmospheric pressure infrared MALDI imaging mass spectrometry for plant metabolomics. Analytical Chemistry, 80(2), 407-420 (2008).

124. Bartels B, Svatos A. Spatially resolved in vivo plant metabolomics by laser ablation-based mass spectrometry imaging (MSI) techniques: LDI-MSI and LAESI. Frontiers in Plant Science, 6, 471 (2015).

125. Huang MZ, Jhang SS, Shiea J. Electrospray laser desorption ionization (ELDI) mass spectrometry for molecular imaging of small molecules on tissues. Methods in Molecular Biology, 1203, 107-116 (2015).

126. Barry JA, Groseclose MR, Robichaud G, Castellino S, Muddiman DC. Assessing drug and metabolite detection in liver tissue by UV-MALDI and IR-MALDESI mass spectrometry imaging coupled to FTICR MS. International Journal of Mass Spectrometry, 377, 448-155 (2015).

127. Bhandari DR, Schott M, Rompp A, Vilcinskas A, Spengler B. Metabolite localization by atmospheric pressure high-resolution scanning microprobe matrix-assisted laser desorption/ionization mass spectrometry imaging in whole-body sections and individual organs of the rove beetle Paederus riparius. Analytical and Bioanalytical Chemistry, 407(8), 2189-2201 (2015).

128. Balluff B, Frese CK, Maier SK et al. De novo discovery of phenotypic intratumour heterogeneity using imaging mass spectrometry. The Journal of Pathology, 235(1), 3-13 (2015).

129. Calligaris D, Feldman DR, Norton I et al. MALDI mass spectrometry imaging analysis of pituitary adenomas for near-real-time tumor delineation. Proceedings of the National Academy of Sciences of the United States of America, 112(32), 9978-9983 (2015).

130. Jones EA, Schmitz N, Waaijer CJ et al. Imaging mass spectrometry-based molecular histology differentiates microscopically identical and heterogeneous tumors. Journal of Proteome Research, 12(4), 1847-1855 (2013).

131. Willems SM, van Remoortere A, van Zeijl R, Deelder AM, McDonnell LA, Hogendoorn PC. Imaging mass spectrometry of myxoid sarcomas identifies proteins and lipids specific to tumour type and grade, and reveals biochemical intratumour heterogeneity. The Journal of Pathology, 222(4), 400409 (2010). 
* One of the first reports demonstrating the ability of MALDI MSI to detect tumour-type and tumour-grade specific biomarkers allowing tumour classification and revealing intratumour heterogeneity.

132. Gruner BM, Winkelmann I, Feuchtinger A et al. Modeling therapy response and spatial tissue distribution of erlotinib in pancreatic cancer. Molecular cancer therapeutics, (2016).

133. Buck A, Halbritter S, Spath C et al. Distribution and quantification of irinotecan and its active metabolite SN-38 in colon cancer murine model systems using MALDI MSI. Analytical and Bioanalytical Chemistry, 407(8), 2107-2116 (2015).

134. Mascini NE, Eijkel GB, ter Brugge P, Jonkers J, Wesseling J, Heeren RM. The use of masS spectrometry imaging to predict treatment response of patient-derived xenograft models of triplenegative breast cancer. Journal of Proteome Research, 14(2), 1069-1075 (2015).

135. Gemoll T, Strohkamp S, Schillo K, Thorns C, Habermann JK. MALDI-imaging reveals thymosin beta-4 as an independent prognostic marker for colorectal cancer. Oncotarget, 6(41), 43869-43880 (2015).

136. Jones EE, Powers TW, Neely BA et al. MALDI imaging mass spectrometry profiling of proteins and lipids in clear cell renal cell carcinoma. Proteomics, 14(7-8), 924-935 (2014).

137. Wang S, Chen X, Luan H et al. Matrix-assisted laser desorption/ionization mass spectrometry imaging of cell cultures for the lipidomic analysis of potentiallipid markers in human breast cancer invasion. Rapid communications in Mass Spectrometry, 30(4), 533-542 (2016).

138. Dekker TJ, Balluff BD, Jones EA et al. Multicenter matrix-assisted laser desorption/ionization mass spectrometry imaging (MALDI MSI) identifies proteomic differences in breast-cancer-associated stroma. Journal of Proteome Research, 13(11), 4730-4738 (2014).

* An internattional multicenter MALDI MSI study identified and validated biomarkers and tumourassociated stromal activation in breast cancer.

139. Jiang L, Chughtai K, Purvine SO et al. MALDI-Mass Spectrometric Imaging Revealing Hypoxia-Driven Lipids and Proteins in a Breast Tumor Model. Analytical Chemistry, 87(12), 5947-5956 (2015).

140. Flatley B, Quaye C, Johnson E et al. Distribution analysis of the putative cancer marker S100A4 across invasive squamous cell carcinoma penile tissue. EuPA Open Proteomics, 7, 1-10 (2015).

141. Cole LM, Clench MR. Mass spectrometry imaging tools in oncology. Biomarkers in Medicine, 9(9), 863-868 (2015).

142. Kriegsmann J, Kriegsmann M, Casadonte R. MALDI TOF imaging mass spectrometry in clinical pathology: a valuable tool for cancer diagnostics (review). International Journal of Oncology, 46(3), 893-906 (2015).

143. McDonnell LA, Corthals GL, Willems SM, van Remoortere A, van Zeijl RJ, Deelder AM. Peptide and protein imaging mass spectrometry in cancer research. Journal of Proteomics, 73(10), 1921-1944 (2010). 
144. Schäfer K-C, Dénes J, Albrecht K et al. In Vivo, In Situ Tissue Analysis Using Rapid Evaporative Ionization Mass Spectrometry. Angewandte Chemie International Edition, 48(44), 8240-8242 (2009).

** One of the first publications on REIMS as a precursor to the iKnife for accurately differentiating malignant tumour from the surrounding healthy tissue during surgical intervention.

145. Dixon RB, Bereman MS, Muddiman DC, Hawkridge AM. Remote mass spectrometric sampling of electrospray- and desorption electrospray-generated ions using an air ejector. Journal of the American Society for Mass Spectrometry, 18(10), 1844-1847 (2007).

146. Iorio E, Mezzanzanica D, Alberti P et al. Alterations of choline phospholipid metabolism in ovarian tumor progression. Cancer Research, 65(20), 9369-9376 (2005).

147. Balog J, Sasi-Szabo L, Kinross J et al. Intraoperative tissue identification using rapid evaporative ionization mass spectrometry. Science Translational Medicine, 5(194), 194 ra193 (2013).

148. Wong S. "Intelligent knife" tells surgeon if tissue is cancerous. (Imperial College London, 2013)

149. Gallagher J. Cancer surgery: Tumour 'sniffing' surgical knife designed. (BBC News, 2013)

150. Nicholson J. iKnife: A Surgical Revolution: sniffing out cancer. (Telegraph Media Group Limited, 2014)

151. REIMS Research System with iKnife Sampling Device. (Waters, 2015)

152. Wong S. Waters Corporation acquires iKnife technology. (Imperial College London, 2014)

153. Strittmatter N, Jones EA, Veselkov KA, Rebec M, Bundy JG, Takats Z. Analysis of intact bacteria using rapid evaporative ionisation mass spectrometry. Chemical Communications, 49(55), 6188-6190 (2013).

154. Strittmatter N, Rebec M, Jones EA et al. Characterization and identification of clinically relevant microorganisms using rapid evaporative ionization mass spectrometry. Analytical Chemistry, 86(13), 6555-6562 (2014).

155. Golf O, Strittmatter N, Karancsi T et al. Rapid evaporative ionization mass spectrometry imaging platform for direct mapping from bulk tissue and bacterial growth media. Analytical Chemistry, 87(5), 2527-2534 (2015).

156. Sachfer KC, Szaniszlo T, Gunther S et al. In situ, real-time identification of biological tissues by ultraviolet and infrared laser desorption ionization mass spectrometry. Analytical Chemistry, 83(5), $1632-1640$ (2011).

157. Schafer KC, Balog J, Szaniszlo T et al. Real time analysis of brain tissue by direct combination of ultrasonic surgical aspiration and sonic spray mass spectrometry. Analytical Chemistry, 83(20), 7729-7735 (2011). 
158. Clark AE, Kaleta EJ, Arora A, Wolk DM. Matrix-Assisted Laser Desorption lonization-Time of Flight Mass Spectrometry: a Fundamental Shift in the Routine Practice of Clinical Microbiology. Clinical Microbiology Reviews, 26(3), 547-603 (2013).

159. Xiao D, Zhang HF, He LH et al. High natural variability bacteria identification and typing: Helicobacter pylori analysis based on peptide mass fingerprinting. Journal of Proteomics, 98, 112 122 (2014).

160. Levine JH, Simonds EF, Bendall SC et al. Data-Driven Phenotypic Dissection of AML Reveals Progenitor-like Cells that Correlate with Prognosis. Cell, 162(1), 184-197 (2015).

161. Amal H, Leja M, Funka K et al. Breath testing as potential colorectal cancer screening tool. International Journal of Cancer, 138(1), 229-236 (2016).

* One of several recent studies on exploiting (easily collectable) breath biomarkers for (colorectal) cancer diagnostics. This study was able to distinguish both cancer from non-cancer patients and advanced cancer from non-advanced cancer, possibly leading to an inexpensive, non-invasive screening tool.

162. Arasaradnam RP, McFarlane MJ, Ryan-Fisher C et al. Detection of Colorectal Cancer (CRC) by Urinary Volatile Organic Compound Analysis. Plos One, 9(9) (2014).

163. Li J, Peng YL, Liu Y et al. Investigation of potential breath biomarkers for the early diagnosis of breast cancer using gas chromatography-mass spectrometry. Clinica Chimica Acta, 436, 59-67 (2014).

164. Phillips M, Bauer TL, Cataneo RN et al. Blinded Validation of Breath Biomarkers of Lung Cancer, a Potential Ancillary to Chest CT Screening. Plos One, 10(12) (2015). 
Figure 1

Workflows in cancer research for LC-MS-based proteomics.

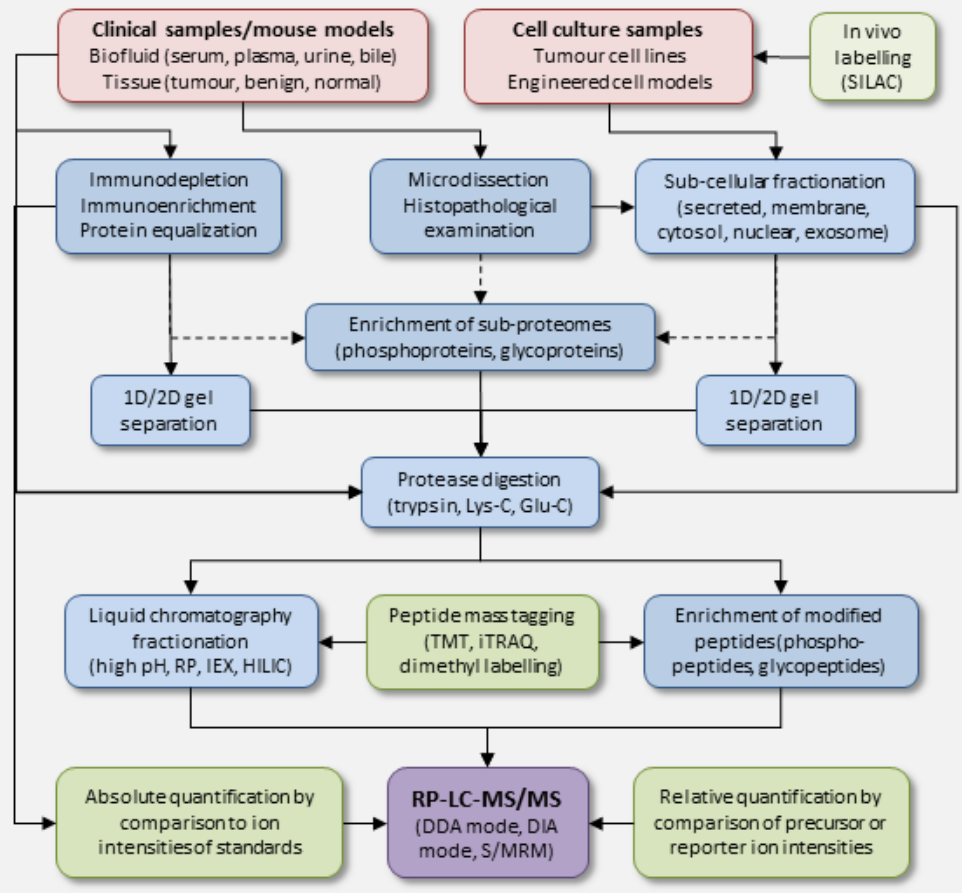


Figure 2

Annotated illustration of the steps involved in sample preparation and data acquisition for MALDI MSI of a tissue sample applying the 'microprobe' approach. Reprinted from Biochimica et Biophysica Acta (BBA) Proteins and Proteomics, 1844, Brian Flatley, Peter Malone, Rainer Cramer, MALDI mass spectrometry in prostate cancer biomarker discovery, 940-949, Copyright (2014), with permission from Elsevier [40].

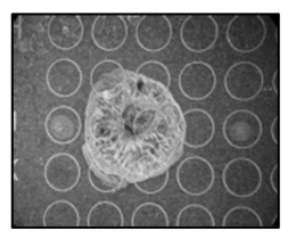

1. Fresh tissue sample is thaw mounted on MALDI target plate
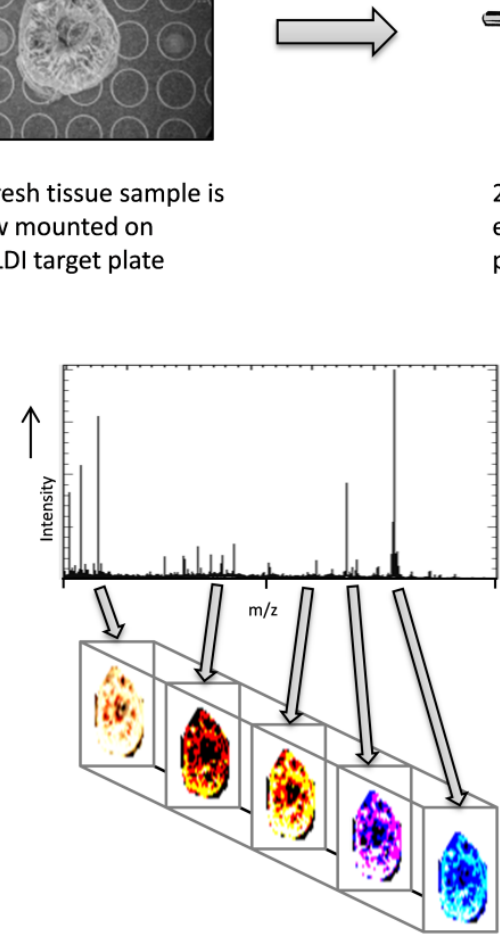

5. Software disentangles the ion intensities from each spectrum and plots them against their $x, y$-coordinates creating ion intensity distribution images for each ion of interest.
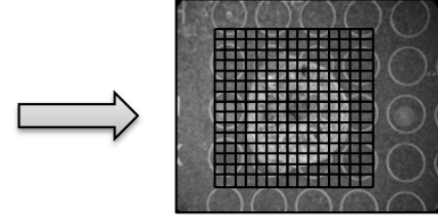

3. The desired image area is selected and divided up into sampling points

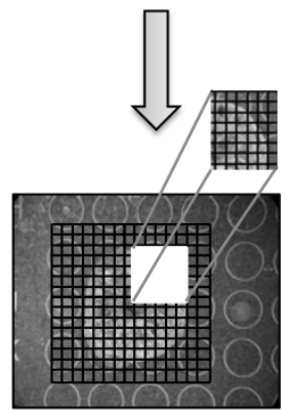

4. At each position an MS spectrum along with its image coordinates is acquired 
Figure 3

Schematic of the REIMS system allowing intra-operative analysis by thermal desorption of material from biological material with an electrosurgical tool. The aerosol is transported through a length of tubing and analysed by QTOF MS. Differences between mass profiles, and thus the biological material, can be evaluated within seconds with multivariate statistical analysis.

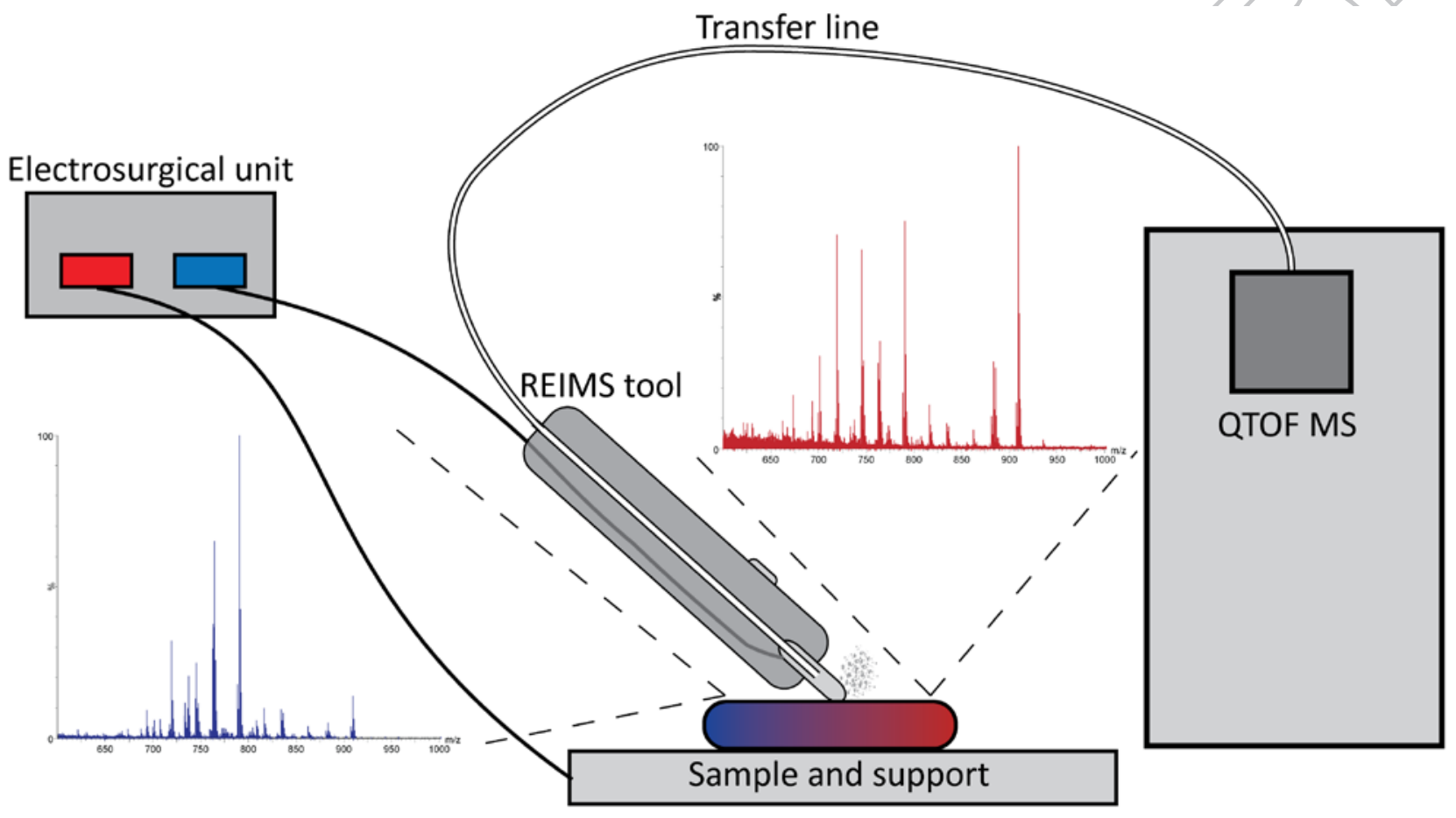

